\title{
Connecting the Dots: Behavioral State Resource Selection in Wild Pigs in the Southeast United States
}

\section{Lindsay Clontz ( $\square$ lindsay.clontz@uga.edu )}

Savannah River Ecology Laboratory, Warnell School of Forestry and Natural Resources, University of Georgia, PO Drawer E, Aiken, SC 29802, USA

Kim M. Pepin

USDA Animal and Plant Health Inspection Service

\section{Kurt C. VerCauteren}

USDA Animal and Plant Health Inspection Service

James C. Beasley

Savannah River Ecology Laboratory

\section{Research}

Keywords: Behavioral analysis, habitat selection, hidden Markov models, resource selection function, wild pig movement

Posted Date: August 18th, 2020

DOI: https://doi.org/10.21203/rs.3.rs-58909/v1

License: (c) (1) This work is licensed under a Creative Commons Attribution 4.0 International License. Read Full License 


\section{Abstract \\ Background}

Invasive wild pigs (Sus scrofa) are behavioral generalists that have the potential to alter ecosystems across broad spatial scales. Elucidating the correlation between wild pig behavior and landscape attributes can aid in the advancement of management strategies for controlling populations.

\section{Methods}

Using GPS data from 49 wild pigs in the southeastern U.S., we used movement characteristics to distinguish and define behaviors and explore the connection between these behaviors and resource selection for both females and males between two distinct seasons based on forage availability. We extracted three biologically relevant behaviors of wild pigs from our movement data using hidden Markov models, which we inferred to represent resting, foraging, and traveling behavioral states. We then used multi-scale resource selection functions to quantify resource selection at the population and home-range scales for each behavioral state.

\section{Results}

Females demonstrated a crepuscular movement pattern in the high-forage season and a variable pattern in the low-forage season, with increased traveling and foraging activity during the daytime and evening hours, while males consistently demonstrated a nocturnal pattern across both seasons. At the population scale, wild pigs selected for forest vegetation types (i.e., upland pines, upland hardwoods, bottomland hardwoods) in both the low- and high-forage seasons, likely reflecting their ubiquitous establishment throughout the landscape. At the home-range scale, wild pigs selected for bottomland hardwoods and dense canopy cover in all behavioral states. In addition, males demonstrated selection for a variety of vegetation types while foraging in the low-forage season compared to the high-forage season and demonstrated an increased use of linear anthropogenic features (e.g., roads) across seasons while traveling.

\section{Conclusions}

Our results demonstrate male and female pigs exhibit clear differences in movement behavior. Further, although wild pigs can establish populations and home ranges in an array of landscapes and habitat types, there are key resources associated with common behaviors they select consistently at a fine scale that can be targeted in conservation and management programs across their invasive range.

\section{Racknround}

Loading [MathJax]/jax/output/CommonHTML/fonts/TeX/fontdata.js

Page $2 / 24$ 
Understanding how animals move throughout landscapes and interact with heterogeneously distributed resources is critical for management and conservation because it provides insight regarding how populations persist and expand, and is thus one of the central goals of ecological research [1,2]. Habitat characteristics that meet specific needs for different behavioral states (e.g., resting vs. foraging) of an animal are usually spatially segregated; therefore, investigation of movement patterns and habitat selection at a fine spatial scale can be used to illustrate the asynchrony of the behavioral strategies employed over time [3]. The observed movement patterns that make up an animal's home range are determined by single movement steps that provide information on the interactions between the individual's external environment and behavioral state $[4,5]$, and represent an animal's response to the environment [6]. For example, in heterogeneous landscapes an animal can respond to variable stimuli such as food availability, cover, and water that can change the trajectory of their movement path [6]. These responses are ultimately the result of a decision-making trade-off every animal has to make about the wide range of competing demands to survive and reproduce[3]. Understanding these underlying finescale interactions with resources allows managers to predict movements of animals in different landscapes to optimize management planning.

Despite the relevance of behavioral-based analyses to conservation and management goals, behaviorspecific resource selection is understudied in most species due to the lack of behavioral context associated with animal location data [7]. Animal behaviors, and the driving factors behind these behaviors, are difficult to quantify in the absence of proper data resolution and analytical tools [8]. However, continued advancements in global positioning system (GPS) tracking technologies and behavioral analysis techniques provide the ability to estimate behavioral states using path characteristics such as turning angles and step-lengths [9-11]. In particular, hidden Markov models (HMM) allow for the exploration of patterns in movement path characteristics created by underlying behavioral states and estimation of the probabilities of transitioning among the identifiable states $[8,12,13]$. Thus, the application of HMMs to animal relocation data can uncover physiological or behavioral states of tracked individuals, which in turn can be used in a resource selection analysis to infer resource selection associated with identified behaviors.

In the case of an adaptable generalist like invasive wild pigs (Sus scrofa), innovative management is critical given the rapid increase in size and distribution of populations throughout their introduced range, in addition to the extensive impacts of this species on anthropogenic and natural systems $[14,15]$. The correlation between behavior and landscape patterns can inform how unexpected populations emerge in new places and continue to expand their range, which is a concern for wildlife managers since wild pigs have the potential to alter ecosystems across broad spatial scales [6, 14-16]. The movement behavior of wild pigs is largely driven by spatio-temporal variation in the distribution of resources throughout the landscape. Wild pigs move in deliberate manners choosing different resource patches depending on their current needs (rest, forage, mates, etc.) relative to what is available and whether or not the tradeoff for accessing these resources is energetically reasonable [17-19]. When targeting these resources for specific behaviors or needs, wild pig movements tend to be methodical, as they often consistently use the Loading [MathJax]/jax/output/CommonHTML/fonts/TeX/fontdata.js cape [20, 21]. These patterns tend to change at 
a broad scale with food availability and dietary shifts throughout the year [22]; however, there is little to no information regarding how wild pigs change fine-scale resource selection and activity patterns associated with specific behaviors as a result of changing landscape characteristics or food availability. Identifying fine-scale behavioral resource selection and activity patterns of wild pigs can inform more effective and efficient selection and development of site-specific management techniques.

In this study, we estimated population-level resource selection patterns (2nd Order; [23]) of wild pigs across two distinct periods (hereafter 'seasons') based on food availability (high- and low-forage availability) in the Southeast U.S. We then used HMM's to distinguish and define movement patterns into associated behavioral states (e.g., resting, foraging, traveling) of wild pigs and evaluated the relationship between behavioral states and resource selection. We tested the hypothesis that wild pigs exhibit differential resource selection patterns depending on their behavioral state (3rd Order; [23]) and availability of forage resources. We expected females and males to demonstrate different movement patterns throughout the day due to differences in reproductive strategies, and we expected these patterns to shift throughout the year based on food availability. Overall, given their association with riparian areas [24-26], we expected behavioral states that aligned with restricted movements (i.e., resting and foraging) to be associated with forested areas proximal to water (i.e., bottomland hardwoods) and areas with greater canopy cover, especially in the warmer and mast (e.g., acorns) producing months. In contrast, given the heterogeneous distribution of riparian areas throughout our study site we expected wild pigs would more extensively use upland pines and linear features such as roads while traveling. During lowforage months, we expected wild pigs to be more opportunistic foragers, leading to more variable patterns of resource selection while foraging.

\section{Methods}

Study area

Our work was conducted on the Savannah River Site (SRS), a $800 \mathrm{~km} 2$ site managed by the U.S. Department of Energy (DOE) on the Georgia-South Carolina border. Although established for industrial activities, facilities and infrastructure comprise a small proportion of the landscape, with most of the landscape being managed by the United States Forest Service (USFS) for timber production and wildlife conservation. The SRS was comprised of approximately 50\% upland pine including loblolly pine (Pinus taeda), longleaf pine (Pinus palustris), and slash pine (Pinus elliottii), 25\% was bottomland hardwood forest, $10 \%$ shrub/herbaceous-dominated areas, $8 \%$ upland hardwoods, and the rest was mixed forest, developed, and barren land. Wild pigs have been managed on the SRS since the early 1950s, when an active live-trap-and-removal program was initiated to mitigate damages caused by wild pigs [27]. This program is managed by USFS and currently removes $~ 1,300-1,800$ pigs annually [28]. Despite this control, there are several thousand wild pigs inhabiting the SRS that are distributed throughout the site [29]. Since the SRS was previously used to manufacture nuclear materials and manage nuclear waste [30], there is limited public access across the site. The diversity of habitat types of the SRS combined with 
the limited public access, diversity of other wildlife species present, and high wild pig densities make the site an ideal location to study movement patterns and resource selection of this species.

\section{Field methods}

We captured wild pigs throughout the SRS from January 2014 - December 2019 using baited-corral traps equipped with a combination of remote-operated and trip-wire mechanisms. We monitored traps using remote cameras (Reconyx PC900, Holmen, WI, USA) to identify dominant sows to receive GPS collars, as well as all breeding-aged males. We used a dart rifle (X-Caliber, Pneu-Dart Inc., Pennsylvania, USA) to anesthetize captured pigs using a combination of butorphanol [0.43 mg/kg], azaperone $[0.36 \mathrm{mg} / \mathrm{kg}$, medetomidine [0.14 mg/kg] (BAM; $0.0064 \mathrm{ml} / \mathrm{kg}$; Wildlife Pharmaceuticals Inc., Colorado, USA) and Ketamine (2.2 mg/kg; Wildlife Pharmaceuticals Inc., Colorado, USA) or Xylazine (2.2 mg/kg; Wildlife Pharmaceuticals Inc., Colorado, USA) and Telazol (4.4 mg/kg; MWI Veterinary Supply, Idaho, USA). While under anesthesia, we recorded sex and assessed age through examination of tooth eruption [31]. We placed uniquely identifiable ear tags in both ears of all captured wild pigs and fit the largest adult female in each sounder (i.e., social unit) and breeding-aged males with an iridium GPS collar (Telonics Gen4 GPS/Iridium System, Telonics, Inc., Mesa, Arizona or VECTRONIC GPS PLUS Globalstar-3, VECTRONIC Aerospace, Coralville, lowa). Anesthetized wild pigs were allowed to recover at the capture site after reversed with a combination of Atipamezole (25 mg/ml; Wildlife Pharmaceuticals Inc.) and Naltrexone (50 mg/ml; Wildlife Pharmaceuticals Inc., Colorado, USA). Collars were programmed to record GPS locations at 30-minute or one-hour intervals and equipped with a mortality sensor that became activated after 12 hours with no movement by the animal. All capture, handling, and procedures was conducted in compliance with the University of Georgia's Animal Care and Use Committee (Protocols: A2012 08 - 004, A2015 05 - 004, and A2018 08-013).

To estimate location error of GPS transmitters, we left a subset of three collars out for 10 days in fixed locations, five days in open vegetation and five days in forest vegetation. We used these data to calculate the average error among fixes for each habitat type.

Identification of movement states

We used HMMs to model the movement characteristics and associated behavioral states of wild pigs for two distinct seasons based on food availability. We considered January through April to represent a lowfood availability time period based on dietary preferences of wild pigs [26], which also generally represents the peak trapping season in the Southeastern U.S. May through December was considered a high-food availability time period when ample amounts of fruits and plants are available throughout the Spring and Summer months, followed by acorns and other mast in Fall and early Winter. Prior to HMM modeling, we subset data for wild pigs with a 30-minute GPS fix rate to one-hour intervals to maintain an equivalent temporal resolution within our dataset. We also removed any duplicate locations (e.g., same date-time stamp) and locations associated with non-pig movements (e.g., locations after mortality). From collars we were able to retrieve and download, less than $0.01 \%$ of locations were $2 \mathrm{D}$ fixes. Therefore, we 
individuals. We also removed the first 48 hours of GPS fixes to account for any potential bias associated with residual anesthetic effects. We used a total sample of 49 wild pigs tracked between January 2014 and December 2019. In the low-forage season (January-April), we tracked 37 wild pigs (21 females, 16 males), and in the high-forage season (May - December) we tracked 41 wild pigs (20 females, 21 males).

We used step-lengths and turning angles as our observational input data in HMMs to differentiate among behaviors. We compared HMM results from 25 different sets of randomly chosen starting values for steplengths and turn angles for each behavioral state to ensure we were capturing global maximums for each behavioral state and that models were numerically stable [10]. We tested HMMs with two and three movement states based on model parsimony [11], but also took into consideration the biological relevance of identified states because model selection criteria sometimes tend to favor models with a greater number of states than makes biological sense [32].

Sex has been found to be an important predictor of wild pig home range size, with males typically having a larger home range and greater movement rates than females [33]. Also, wild pigs have demonstrated seasonal differences in home range size and habitat selection based on resource availability [19, 26, 34]. Therefore, we expected sex-specific and seasonal-specific differences in the movement parameters associated with each behavioral state and differences in transition probabilities among states throughout the diel period. We ran HMMs separately for males and females in both the low- and high-forage seasons and tested for an additive effect of time of day on the probability of transitioning among states. We selected the most parsimonious model for both seasons for females and males separately using Akaike Information Criterion (AIC; [35]). Next, we decoded the most likely sequence of states to have produced each location or step in the movement path of each wild pig given the most parsimonious model using the Viterbi algorithm [13]. All computations were done using the moveHMM package [10] in the statistical computing software R 3.6.1 [36]. Using the top ranked HMM for both females and males in both seasons (see results), we partitioned GPS locations into three behavioral states that we perceived to likely represent resting, foraging, and traveling, and quantified resource selection for both sexes in each season and behavioral state at the third order (i.e., home range) spatial scale (See below; [23]).

Resource selection analyses

\section{Habitat covariates}

We generated individual raster layers for four types of vegetative cover from the 2016 National Land Cover Database (NLCD) raster layer (30 × 30 m-resolution; [37]) for resource selection analyses: (1) upland pines, (2) bottomland hardwoods, (3) shrub and herbaceous, and (4) upland hardwoods. We also characterized the distribution of streams and roads within our study area from existing SRS geospatial layers. We classified primary roads as those that were paved and routinely used for travel by SRS employees, whereas secondary roads were unpaved gravel and/or logging roads. Lastly, we used the NLCD 2016 USFS tree canopy cover raster ( $30 \times 30$ m-resolution) to estimate the percent canopy cover. 
We selected a $481 \mathrm{~km}^{2}$ area within the SRS to represent the study area for this analysis by generating a minimum convex polygon (MCP) around all GPS locations and buffering it by $1.2 \mathrm{~km}$ to account for any long distance movements $[26,33]$. We quantified habitat availability for the population at the second order by systematically sampling the study area (every 3rd pixel, i.e., $90 \mathrm{~m}$; available locations) and comparing these locations to locations systematically sampled (every 3rd pixel, i.e., 90 m; used locations) within a $95 \%$ fixed kernel home range generated for each individual using the adehabitat package with the reference bandwidth (href) smoothing parameter [38] in the statistical computing software R 3.6.1 [36]. We generated individual home ranges for both seasons to compare seasonal shifts in home range distribution. We used the Euclidean distance tool in ArcGIS 10.7.1 (Environmental System Research Institute, Inc., Redlands, CA, USA) to calculate the distance to each of the habitat covariates for used and available locations to provide a less ambiguous approach compared to a classification- or categoricalapproach [39]. We evaluated used locations specific to each individual home range against the same set of available locations throughout the study area for all individuals. We calculated Pearson's correlation coefficients to test for collinearity between each of our habitat covariates and excluded covariates with Pearson's $|r|>0.6$ [3]. We then fit a global generalized linear model (GLM) with binomial error distribution (logistic regression) and logit link to the used-available data individually for both sexes in both the lowforage and high-forage seasons. We did not use a model selection technique to rank candidate models, so all models contain the same beta coefficients in order to directly compare coefficient estimates across

sexes and seasons [40]. We standardized all variables prior to model development $\left[\left(x_{i^{-}}{ }^{\bar{x}}\right) / \mathrm{s}\right]$ and then back-transformed all coefficients to represent $100 \mathrm{~m}$ increments for interpretation. All GLM models were computed using the Ime4 package in $\mathrm{R}$ version 3.6.1 [36, 41]. We assessed how well the second order model explained the data using area under the receiver-operating characteristic curve (AUC; [42-44]), which we computed using the pROC package in $\mathrm{R}$ version 3.6.1 [36, 45]. A value of 0.5 indicates the model provides predictions that are no better than random predictions, but values greater than 0.7 indicate a better model fit with more meaningful predictions [43].

\section{Third order}

To assess fine-scale resource selection of wild pigs, we used a resource selection function (RSF) framework [46] to compare resource selection of wild pigs across the three behavioral states associated with the movement path characteristics identified from the HMM (i.e., resting, foraging, and traveling). We quantified habitat availability for individuals at the third order by comparing GPS locations (i.e., used locations) to systematically sampled locations (every 3rd pixel, i.e., $90 \mathrm{~m}$; available locations) within home ranges across each of the aforementioned covariates (see above). The sampling framework provided inference on the similarities and differences of wild pig resource selection in three prominent behavioral states that can be extracted to the population level. We used a generalized linear mixed model (GLMM) with binomial error distribution (logistic regression), logit link, and a random intercept to account for an unbalanced distribution of samples among individuals (i.e., variable numbers of GPS fixes) [47].

We standardized all variables prior to model development $\left[\left(x_{i}-\mathrm{x}\right) / \mathrm{s}\right]$ and then back transformed 
coefficients for interpretation. All GLMM models were computed using the Ime4 package in $\mathrm{R}$ version 3.6.1 [36, 41].

We calculated Pearson's correlation coefficients to test for collinearity between each of our habitat covariates and excluded covariates with Pearson's $|r|>0.6$ [3]. We created a global model including all covariates for each sex in each behavioral state in each season (i.e., 2 sexes 3 behavioral states 2 seasons $=12 \mathrm{RSFs}$ ). As with our second-order analyses, we did not use a model selection technique so that we could more directly compare estimates across behavioral states, sexes, and seasons [40], and we used AUC to assess how well the model explained the data [42-44].

\section{Results}

Identification of movement states

We used a sample of 49 wild pigs tracked between January 2014 and December 2019, resulting in 117,150 validated and cleaned GPS locations (Table 1). In the low-forage season (January-April), we tracked 37 wild pigs ( 21 females, 16 males), resulting in 47,983 GPS locations, and in the high-forage season (May - December) we tracked 41 wild pigs (20 females, 21 males), resulting in 69,177 GPS locations (Table 1). From these data, we estimated movement path characteristics (e.g., behavioral states) for 29,433 and 42,277 locations for females during the low and high-forage seasons, respectively. For males, we had 18,550 locations during the low-forage season and 26,900 during the high-forage season to inform our analyses (Table 1). We determined average collar error in forested vegetation to be $22.3 \mathrm{~m}$ and in open vegetation to be $11.9 \mathrm{~m}$.

Table 1

Summary global positioning system (GPS) information and average step-lengths ( \pm SE) and turning angles of female and male wild pigs (Sus scrofa) on the Savannah River Site in South Carolina and Georgia based on GPS locations from January 2014 - December 2019.

\begin{tabular}{|c|c|c|c|c|c|c|c|}
\hline Sex & $\begin{array}{l}\text { Months } \\
\text { (Season) }\end{array}$ & $\begin{array}{l}\text { Number } \\
\text { of Pigs }\end{array}$ & $\begin{array}{l}\text { Number } \\
\text { of } \\
\text { Locations }\end{array}$ & $\begin{array}{l}\text { Mean } \\
\text { Number } \pm \\
\text { SE of } \\
\text { Locations }\end{array}$ & $\begin{array}{l}\text { Range of } \\
\text { Locations } \\
\text { per } \\
\text { Individual }\end{array}$ & $\begin{array}{l}\text { Avg. } \\
\text { Step- } \\
\text { length } \pm \\
\text { SE (m) }\end{array}$ & $\begin{array}{l}\text { Avg. } \\
\text { Tuming } \\
\text { Angle } \\
\text { (radians) }\end{array}$ \\
\hline \multirow[t]{2}{*}{ Females } & $\begin{array}{l}\text { January - } \\
\text { April }\end{array}$ & 21 & 29433 & $\begin{array}{l}1401.57 \pm \\
137.97\end{array}$ & $240-2987$ & $\begin{array}{l}124.32 \\
\pm 1.23\end{array}$ & $\begin{array}{l}1.72 \pm \\
0.006\end{array}$ \\
\hline & $\begin{array}{l}\text { May - } \\
\text { December }\end{array}$ & 20 & 42277 & $\begin{array}{l}2113.85 \pm \\
360.46\end{array}$ & $432-5843$ & $\begin{array}{l}144.97 \\
\pm 1.06\end{array}$ & $\begin{array}{l}1.68 \pm \\
0.005\end{array}$ \\
\hline \multirow[t]{2}{*}{ Males } & $\begin{array}{l}\text { January - } \\
\text { April }\end{array}$ & 16 & 18550 & $\begin{array}{l}1159.38 \pm \\
174.59\end{array}$ & $328-2232$ & $\begin{array}{l}186.01 \\
\pm 2.36\end{array}$ & $\begin{array}{l}1.67 \pm \\
0.007\end{array}$ \\
\hline & $\begin{array}{l}\text { May - } \\
\text { December }\end{array}$ & 21 & 26900 & $\begin{array}{l}1280.95 \pm \\
276.67\end{array}$ & $239-4263$ & $\begin{array}{l}229.18 \\
\pm 2.31\end{array}$ & $\begin{array}{l}1.62 \pm \\
0.006\end{array}$ \\
\hline
\end{tabular}

We concluded a three-state HMM with a Gamma distribution for step-length, a wrapped Cauchy 
in both seasons best, was the most supported (i.e., lowest AIC), and provided the most reasonable biological interpretation (see Additional file 1: Table S1). From the three-state HMMs, we identified three general types of movements associated with common behavioral states: (1) a state with short steplengths and high degrees of turning concentrated around $\pi$ radians; (2) a state with short to intermediate step-lengths and high degrees of turning concentrated around $\pi$ radians; and (3) a state with long steplengths and more straightforward movements with turning concentrated around 0 radians, which likely represents resting, foraging, and traveling behaviors, respectively (Table 2; Fig. 1, Fig. 2).

Table 2

Average step-lengths ( \pm SE) and turning angles for each designated behavioral state by sex in the 3-state HMMs with the additive effect of hour of day of wild pigs (Sus scrofa) on the Savannah River Site in South Carolina and Georgia based on GPS locations from two distinct seasons based on forage availability, low-forage availability (January - April) and high-forage availability (May - December).

\begin{tabular}{|c|c|c|c|c|c|c|}
\hline & \multicolumn{3}{|c|}{ January - April } & \multicolumn{3}{|c|}{ May - December } \\
\hline \multicolumn{7}{|l|}{$\begin{array}{l}\text { Mean Parameters - } \\
\text { Females }\end{array}$} \\
\hline & Resting & Foraging & Traveling & Resting & Foraging & Traveling \\
\hline $\begin{array}{l}\text { Average Step- } \\
\text { lengths } \pm S E(m)\end{array}$ & $\begin{array}{l}11.4 \pm \\
7.38\end{array}$ & $\begin{array}{l}37.70 \pm \\
23.24\end{array}$ & $\begin{array}{l}244.30 \pm \\
220.97\end{array}$ & $\begin{array}{l}19.25 \pm \\
13.08\end{array}$ & $\begin{array}{l}67.29 \pm \\
48.32\end{array}$ & $\begin{array}{l}276.62 \pm \\
227.91\end{array}$ \\
\hline $\begin{array}{l}\text { Average Turn Angles } \\
\text { (radians) }\end{array}$ & 3.14 & 3.11 & 0.001 & -3.11 & 3.14 & 0.07 \\
\hline \multicolumn{7}{|l|}{$\begin{array}{l}\text { Mean Parameters - } \\
\text { Males }\end{array}$} \\
\hline $\begin{array}{l}\text { Average Step- } \\
\text { lengths } \pm \text { SE (m) }\end{array}$ & $\begin{array}{l}9.68 \pm \\
6.31\end{array}$ & $\begin{array}{l}33.00 \pm \\
23.11\end{array}$ & $\begin{array}{l}398.43 \pm \\
385.81\end{array}$ & $\begin{array}{l}14.27 \pm \\
9.56\end{array}$ & $\begin{array}{l}52.46 \pm \\
34.67\end{array}$ & $\begin{array}{l}420.70 \pm \\
406.12\end{array}$ \\
\hline $\begin{array}{l}\text { Average Turn Angles } \\
\text { (radians) }\end{array}$ & -3.12 & -3.12 & -0.04 & 3.11 & 3.13 & 0.02 \\
\hline
\end{tabular}

Male and female wild pigs exhibited clear differences in movement behavior. Specifically, average steplengths differed between sexes, and males and females exhibited differences in partitioning of behavioral states across the diel period (Fig. 3). Males typically traveled farther than females in hour segments (Table 1) and demonstrated an evident nocturnal movement strategy by traveling mainly throughout the nighttime hours and resting during most of the day (Fig. 3). Males also maintained a consistent movement pattern across seasons. In contrast, females exhibited their longest step-lengths in the evening hours around dusk in the low-forage season and had a variable behavioral pattern throughout the remainder of the day. However, in high-forage months females had a crepuscular movement pattern with peak traveling and foraging movements around dawn and dusk (Fig. 3). Step-lengths for both sexes were longer during the resting and foraging behaviors in the high-forage season compared to the low-forage season (Table 2). 


\section{Second Order}

Female wild pigs selected all vegetation types (i.e., upland pines, upland hardwoods, bottomland hardwoods, shrub/herbaceous) across our study area in their home-range placement at the second order in both the low and high-forage seasons (Fig. 4), likely reflecting the ubiquitous establishment of wild pigs across the Savannah River Site [29]. Females also selected locations closer to streams and avoided areas near roads. In contrast, males in the low-forage season selected home ranges in or near upland pines, shrub/herbaceous vegetation, and bottomland hardwoods (Fig. 4). In addition, males selected areas close to streams and primary roads. During the high-forage season, males selected resources similarly to the low-forage season, with the main difference of primary roads no longer being an important driver of home range placement (Fig. 4). AUC values in the low-forage season models for females and males were $0.62,0.66$ and in the high-forage season as $0.64,0.59$, respectively.

\section{Third order}

During the resting state, female wild pigs in the low-forage season strongly selected areas in or close to bottomland hardwoods and shrub/herbaceous habitats (Fig. 5). For example, there was a $23 \%$ decrease in use for every $100 \mathrm{~m}$ farther away from bottomland hardwoods and a $10 \%$ decrease in use for every $100 \mathrm{~m}$ farther away from shrub and herbaceous habitats. During the high-forage season, female wild pigs selected resting areas similarly to the low-forage season with the addition of a strong selection for upland hardwoods. Also, the resting model for females in both seasons indicated they avoided areas near secondary roads and streams (Fig. 5). Similarly, males selected resting areas in or close to bottomland hardwoods, upland hardwoods, and shrub/herbaceous communities in both seasons. However, males differed between seasons in selecting to rest near streams during the low-forage season but not during the high-forage season, with a $5.4 \%$ decrease in use for every $100 \mathrm{~m}$ farther away from a stream during the low-forage season (Fig. 5). Females did not select streams at the home-range scale during either season.

Throughout the foraging state, females differed in relative probability of selection between the low- and high-forage seasons (Fig. 5). For example, females selected areas near primary roads and bottomland hardwoods during the low-forage season, yet during the high-forage season they selected areas near upland hardwoods and upland pines in addition to areas near primary roads and bottomland hardwoods. Males demonstrated a more variable selection while foraging in the low-forage season including shrub/herbaceous, bottomland hardwoods, and both secondary and primary roads; however, during the high-forage season males concentrated foraging in areas near or in bottomland hardwood vegetation (Fig. 5). During the high-forage season, males exhibited a $23 \%$ decrease in use for every $100 \mathrm{~m}$ farther from bottomland hardwoods. In addition, the selection for areas with a high percentage of canopy cover was consistent between sexes and seasons within the foraging behavioral state (Fig. 5).

Resource selection during the traveling behavioral state was similar between seasons for females and males. Females selected primary roads and bottomland hardwoods when traveling in both seasons, with 
vegetation, primary and secondary roads, and bottomland hardwoods while traveling in both seasons (Fig. 5). For example, in the high-foraging season, males displayed a $16 \%$ decrease in use during the traveling state for every $100 \mathrm{~m}$ farther from secondary roads (Fig. 5).

The AUC values, which provided a comparison for overall fit for resting, foraging, and traveling behavioral states in low- and high-forage seasons were $0.81,0.79,0.76$ and $0.73,0.75,0.73$ for females and 0.77 , $0.80,0.70$ and $0.77,0.80,0.74$ for males, respectively.

\section{Discussion}

Using an extensive dataset of wild pig GPS data across a heterogeneous landscape in the Southeastern U.S., here we demonstrate the differential resource selection tactics employed by wild pigs at both broad (i.e., home range placement) and fine (i.e., within-home-range, behavior-specific) spatial scales for males and females across two distinct seasons based on forage availability. Movement path characteristics of wild pigs in our study were influenced by a combination of local and landscape-level habitat attributes such as bottomland and upland hardwoods, streams, secondary roads, and shrub/herbaceous vegetation communities. However, while males and females tended to select areas to establish home ranges (population scale) similarly, we found notable differences in the fine-scale use of habitats within home ranges between sexes and seasons, although both males and females consistently selected bottomland hardwood habitats and areas with extensive canopy cover. Further, through the use of step lengths and turn angles to define behavioral-based resource selection patterns, we found that females and males differed in daily movement patterns and that wild pigs exhibited differential selection of landscape attributes among behavioral states.

Based on the results of our HMM analyses, we distinguished three biologically relevant behavioral states generally based on patterns in the movement characteristics of wild pigs (i.e., resting, foraging, traveling). Previous studies have identified similar patterns for other species [9,32, 48]; however, behavioral states associated with movement characteristics may be assigned differently depending on prior knowledge of different animal species and fix rate at which GPS data were collected. Although wild pigs exhibit several behaviors that correspond to short and intermediate step-lengths and tight turn angles (e.g., resting, wallowing, rubbing, tusking, foraging, etc.), for management purposes of wild pigs classifying behaviors into resting, foraging, and traveling encapsulated the most common and consistent motivations of space use (e.g., forage, cover, thermoregulation; [26]).

Both females and males decreased movements or traveling behavior in the mid-day, most likely due to the association with high temperatures in the southeast during the high-forage season [26, 33], and males maintained a consistent nocturnal pattern between seasons. However, females exhibited seasonal differences in movement patterns that were likely related to reproductive stages of the reproductive cycle throughout the year, as the timing of farrowing is related to the seasonal availability of forage [49, 50]. In the low-forage season, which corresponded with peak farrowing in our study area ([49]; Chinn, unnublichod datal fomaloc domnnctratod a charn incrase in traveling at dusk along with an increase in Loading [MathJax]/jax/output/CommonHTML/fonts/TeX/fontdata.js

Page $11 / 24$ 
foraging throughout daytime hours as well as a slight increase in resting mid-day followed by a distinct increase in resting throughout nighttime hours. However, during the high-forage season when farrowing rates are lower and juvenile pigs are more mobile, females demonstrated a more crepuscular movement pattern compared to the low-forage season. Pre-parturition and parturition-associated behaviors in some wildlife species, such as wild pigs, are associated with reduced movements and home range sizes [22, 33]. Irregular and/or reduced movements can continue after parturition causing an abnormal activity pattern in females [50], as we found throughout the low-forage season. Males and females have different reproductive tendencies and responsibilities as a polygamous species [51] in which males breed multiple females and provide no parental care. Therefore, behavioral differences between sexes likely reflect different reproductive obligations [50] and should be a focus for further research.

Wild pigs can demonstrate multiple behaviors in similar vegetation types [52], but there are certain habitat characteristics and vegetation types that facilitate specific behaviors (e.g., relocation using roads; [6]). Although wild pigs are ecological generalists, they exhibit spatio-temporal differences in resource selection that reflect underlying biological needs (e.g., thermoregulation; [26, 34]). At the population and home-range scale, our analyses revealed that while male and female wild pigs exhibited similarities in resource selection in the low-forage season, notable differences between sexes were apparent. Dense cover and areas proximal to water (i.e., bottomland hardwoods) are two key vegetation characteristics that provide resources that pigs require [26], and we found that females and males selected for bottomland hardwoods and areas with high percentages of canopy cover in every behavioral state during the low-forage season. In addition, wild pigs forage on subterranean foods such as roots and tubers when other sources are scarce [26,53,54]; therefore, selecting bottomland hardwoods and areas with extensive canopy cover coincide with these forage types and provide access to water and cover.

While foraging, males selected for a variety of vegetation types and structures throughout the low-forage season. For example, at both the population and the home-range scales males demonstrated a change in selection for primary roads between seasons. In the low-forage season, males established home ranges near primary roads and selected for areas closer to primary roads in all three behavioral states. Also, males avoided secondary roads at the population scale, but selected for secondary roads in the foraging and traveling states at the home-range scale. The selection for areas near or along both primary and secondary roads while foraging is likely due to the decrease in resources in adjacent natural areas and the consistent availability of grasses along open roadsides during the low-forage season [54, 55], which coincides with the increase in use of urbanized and anthropogenic areas when natural forage is scarce $[56,57]$. Lastly, during the resting state females demonstrated selection for shrub and herbaceous vegetation, which was characterized by a mixture of areas in early successional stages and grasslands that both typically occurred together along secondary roads, power lines, and streams, while males selected for this vegetation type in every behavioral state. Areas dominated by this vegetation type most likely provided forage, cover, and easy access to linear features when transitioning to traveling in the lowforage season. 
During the high-forage season, neither males nor females selected for primary or secondary roads at the population scale. However, at the home-range scale males selected for areas closer to secondary roads while traveling but avoided these areas when foraging and resting. Selecting for anthropogenic and natural linear features can help increase an animal's pace (step-length) and directional movement, which can assist in traversing the landscape quickly when dispersing, searching for a mate, or transitioning between resting and foraging behaviors $[26,58,59]$. Also, males selected primarily for bottomland hardwoods while foraging in the high-forage season, and females selected for upland and bottomland hardwoods during all behavioral states, likely reflecting the availability of food, water, and cover in these habitats [26]. Selection for bottomland hardwoods is most likely associated with mast producing hardwoods (e.g., oak acorns) and productive plants in the understory throughout summer months, as well as dense cover and proximity to water. Lastly, throughout the high-forage season, males and females selected for streams at the population scale but avoided streams at the home-range scale, which is likely due to the extensive stream system throughout the SRS and the ability to access dense cover during times of extreme temperatures. Other studies have demonstrated the insignificance of streams at the home-range scale throughout certain times of the year when water is generally present throughout the landscape [59].

Wild pigs exhibit substantive behavioral plasticity and can adjust their life history strategies such as daily activity patterns to decrease human interaction in populated areas as well as their diet throughout the year and in a variety of climatic conditions to benefit their long-term survival depending on local environmental conditions [26, 56, 60,61]. Although our study was limited to the Southeast U.S., wild pigs demonstrate consistent selection patterns for vegetation types associated with certain resources (i.e., water, mast, etc.; [22, 26, 62-64]). Therefore, our findings are likely applicable in similar areas throughout this species' native and introduced range. However, further research should focus on wild pig behavioral state resource selection in other geographic regions to elucidate spatio-temporal differences in wild pig behavior across areas of differing climate and resource base.

While our general findings are consistent with previous literature on wild pig habitat selection, through the investigation of fine-scale movement patterns coupled with behavioral-based resource selection we were able to demonstrate pigs exhibit clear differences in temporal patterns of activity and selection of habitats among behavioral states. For example, male wild pigs strongly selected for secondary roads while traveling during both seasons but avoided or selected them less while in the foraging and resting behavioral states. Similarly, females demonstrated a selection for shrub/herbaceous communities while resting during both seasons but avoided or selected them less while foraging and traveling. Thus, delineating GPS observational data into unique behavioral states provides unique insights into the relative importance of environmental attributes critical to the conservation or management of a species that may otherwise be obscured through more coarse-scale resource selection approaches [3].

\section{Conclusions}


Accounting for behavior when studying habitat selection can provide more useful and accurate information for managers and conservationists. Specifically, for wild pigs, understanding the driving forces of resource selection at a fine-scale can inform when, where, and how to deploy traps, toxicants, attractants, etc. to ensure visitations occur quickly and consistently [26], as well as areas to focus mitigation efforts from wild pig damage. Our results indicated vegetation class and other landscape features consistently determined habitat use by wild pigs when resting, foraging, and traveling. Therefore, targeting specific vegetation types, features, and times throughout the diel period could provide an advantage for managers when strategically employing specific management techniques in areas where wild pigs would be most vulnerable. For example, to increase efficiency and effectiveness of management techniques such as hunting and aerial gunning, targeting wild pigs during active hours of the day and in habitat types they select for during the foraging and/or traveling behavioral states could greatly increase the number of pigs removed during these management processes.

\section{Abbreviations}

GPS

Global Positioning System

HMM

Hidden Markov Model

DOE

Department of Energy

USFS

United States Forest Service

SRS

Savannah River Site

AIC

Akaike Information Criterion

NLCD

National Land Cover Data

MCP

Minimum Convex Polygon

GLM

Generalized Linear Model

GLMM

Generalized Linear Mixed Model

AUC

Area under the receiver-operating curve

RSF

Resource Selection Function 


\section{Declarations}

\section{Ethics approval and consent to participate}

All capture, handling, and procedures was conducted in compliance with the University of Georgia's Animal Care and Use Committee (Protocols: A2012 08-004, A2015 05-004, and A2018 08-013).

\section{Consent for publication}

Not applicable.

\section{Availability of data and materials}

The datasets used and/or analyzed during the current study are available from the corresponding author upon request.

\section{Competing interests}

The authors declare they have no competing interests.

\section{Funding}

This material is based upon work supported by the US Department of Energy under Award No. DEEM0004391 to the UGA Research Foundation and the US Department of Agriculture's Animal and Plant Health Inspection Service.

\section{Authors' contributions}

LMC and JCB conceived the study. LMC wrote the paper with input from JCB, KMP, and KCV. LMC carried out fieldwork and analyzed the data with input from KMP. JCB and KCV secured funding. All author(s) edited and approved the final manuscript.

\section{Acknowledgments}

We thank the numerous field technicians, graduate students, and other research personnel including Sarah Chinn, Peter Schlichting, and Dave Keiter who assisted with this research, as well as the USFS for their assistance in the capture of wild pigs used in this study. Thanks also to M. Kohl for his insight on data analysis techniques. This material is based upon work supported by the US Department of Energy under Award No. DE-EM0004391 to the UGA Research Foundation and the US Department of Agriculture's Animal and Plant Health Inspection Service.

\section{Disclaimer}

This manuscript was prepared as an account of work sponsored by an agency of the United States Gnvarnmont Naithor tho I Initod Statoc Gnvornmont nor any agency thereof, nor any of their employees, Loading [MathJax]/jax/output/CommonHTML/fonts/TeX/fontdata.js 
makes any warranty, express or implied, or assumes any legal liability or responsibility for the accuracy, completeness, or usefulness of any information disclosed, or represents that its use would not infringe privately owned rights. Reference herein to any specific commercial product, process, or service by trade name, trademark, manufacturer, or otherwise does not constitute or imply its endorsement, recommendation, or favoring by the United States Government or any agency thereof. The views and opinions of the authors expressed herein do not necessarily state or reflect those of the United States Government or any agency thereof.

\section{References}

1. Wiens JA, Stenseth NChr, Van Horne B, Ims RA. Ecological mechanisms and landscape ecology. Oikos. 1993;66(3):369-80.

2. Ellner SP, McCauley E, Kendall BE, Briggs CJ, Hosseini PR, Wood SN, et al. Habitat structure and population persistence in an experimental community. Nature. 2001;412:538-43.

3. Roever $\mathrm{CL}$, Beyer HL, Chase MJ, van Aarde RJ. The pitfalls of ignoring behaviour when quantifying habitat selection. Diversity and Distributions. 2014;20(3):322-33.

4. Moorcroft PR, Moorcroft P, Lewis MA. Mechanistic home range analysis. Princeton University Press; 2006. $204 \mathrm{p}$.

5. Boerger L, Dalziel BD, Fryxell JM. Are there general mechanisms of animal home range behaviour? A review and prospects for future research. Ecology Letters. 2008;11(6):637- 50.

6. Forester JD, Ives AR, Turner MG, Anderson DP, Fortin D, Beyer HL, et al. State-Space Models link elk movement patterns to landscape characteristics in Yellowstone National Park. Ecological Monographs. 2007;77(2):285-99.

7. Beyer HL, Haydon DT, Morales JM, Frair JL, Hebblewhite M, Mitchell M, et al. The interpretation of habitat preference metrics under use-availability designs. Philosophical Transactions of the Royal Society B: Biological Sciences. 2010 Jul 27;365(1550):2245- 54.

8. Patterson TA, Basson M, Bravington MV, Gunn JS. Classifying movement behaviour in relation to environmental conditions using hidden Markov models. Journal of Animal Ecology. 2009;78(6):1113-23.

9. Franke A, Caelli T, Hudson RJ. Analysis of movements and behavior of caribou (Rangifer tarandus) using hidden Markov models. Ecological Modelling. 2004 Apr 1;173(2):259- 70.

10. Michelot T, Langrock R, Patterson T. moveHMM: An R package for the analysis of animal movement data. 2016;7(11):20.

11. Leos-Barajas V, Gangloff EJ, Adam T, Langrock R, van Beest FM, Nabe-Nielsen J, et al. Multi-scale modeling of animal movement and general behavior data using hidden markov models with hierarchical structures. JABES. 2017 Sep 1;22(3):232-48.

12. Schick RS, Loarie SR, Colchero F, Best BD, Boustany A, Conde DA, et al. Understanding movement data and movement nrocesses current and emeraing directions. Ecology Letters. 2008;11(12):1338Loading [MathJax]/jax/output/CommonHTML/fonts/TeX/fontdata.js 
50.

13. Zucchini W, MacDonald IL, Langrock R, MacDonald IL, Langrock R. Hidden Markov Models for Time Series: An Introduction Using R. Chapman and Hall/CRC; 2009. 275 p.

14. Beasley JC, Ditchkoff SS, Mayer JJ, Smith MD, Vercauteren KC. Research priorities for managing invasive wild pigs in North America. The Journal of Wildlife Management. 2018;82(4):674-81.

15. VerCauteren KC, Mayer JJ, Beasley JC, Ditchkoff SS, Roloff GJ, Strickland BK. Introduction. In: VerCauteren KC, Beasley JC, Ditchkoff SS, Mayer JJ, Roloff GJ, Strickland BK, editors. Invasive wild pigs in North America: ecology, impacts, and management. Boca Raton, FL, USA: CRC Press; 2020. p. [1-5].

16. Barrios-Garcia M, Ballari S. Impact of wild boar (sus scrofa) in its introduced and native range: a review. Biological Invasions. 2012;14(11):2283-300.

17. Fortin D, Beyer HL, Boyce MS, Smith DW, Duchesne T, Mao JS. Wolves influence elk movements: behavior shapes a trophic cascade in Yellowstone National Park. Ecology. 2005;86(5):1320-30.

18. Forester JD, Im HK, Rathouz PJ. Accounting for animal movement in estimation of resource selection functions: sampling and data analysis. Ecology. 2009;90(12):3554-65.

19. Wilber MQ, Chinn SM, Beasley JC, Boughton RK, Brook RK, Ditchkoff SS, et al. Predicting functional responses in agro-ecosystems from animal movement data to improve management of invasive pests. Ecological Applications. 2020;30(1):e02015.

20. Hanson RP, Karstad L. Feral swine in the southeastern United States. The Journal of Wildlife Management. 1959;23(1):64.

21. Oliveira-Santos LGR, Forester JD, Piovezan U, Tomas WM, Fernandez FAS. Incorporating animal spatial memory in step selection functions. Journal of Animal Ecology. 2016;85(2):516-24.

22. Mayer JJ. Wild pig behavior. In: Mayer JJ, Brisbin IL, editors. Wild pigs: biology, damage, control techniques and management. 2009. p. [77-104].

23. Johnson $\mathrm{DH}$. The comparison of usage and availability measurements for evaluating resource preference. Ecology. 1980;61(1):65-71.

24. Singer FJ, Otto DK, Tipton AR, Hable CP. Home ranges, movements, and habitat use of european wild boar in Tennessee. Journal of Wildlife Management. 1981;45(2):343-53.

25. Gaston W, Armstrong J, Arjo W, Stribling HL. Home Range and Habitat Use of Feral Hogs (Sus scrofa) on Lowndes County WMA, Alabama. National Conference on Feral Hogs [Internet]. 2008 Apr 15; Available from: https://digitalcommons.unl.edu/feralhog/6

26. Gray SM, Roloff GJ, Montgomery RA, Beasley JC, Pepin KM. Wild pig spatial ecology and behavior. In: VerCauteren KC, Beasley JC, Ditchkoff SS, Mayer JJ, Roloff GJ, Strickland BK, editors. Invasive wild pigs in North America: ecology, impacts, and management. Boca Raton, FL, USA: CRC Press; 2020. p. [33-56].

27. Mayer JJ, Beasley JC, Boughton R, Ditchkoff SS. Wild Pigs in Southeastern North America. In: VerCauteren KC, Beaslev JC, Ditchkoff SS, Maver JJ, Roloff GJ, Strickland BK, editors. Invasive Wild Loading [MathJax]/jax/output/CommonHTML/fonts/TeX/fontdata.js 
Pigs in North America: Ecology, Impacts, and Management. Boca Raton, FL, USA: CRC Press; 2020. p. [369-402].

28. Beasley JC, Grazia TE, Johns PE, Mayer JJ. Habitats associated with vehicle collisions with wild pigs. Wildlife Res. 2014;40(8):654-60.

29. Keiter DA, Davis AJ, Rhodes OE, Cunningham FL, Kilgo JC, Pepin KM, et al. Effects of scale of movement, detection probability, and true population density on common methods of estimating population density. Scientific Reports. 2017 Aug 25;7(1):9446.

30. White DL, Gaines KF. The Savannah River Site: Site Description, Land Use and Management History. 2000;8-17.

31. Mayer JJ, Smyser TJ, Piaggio AJ, Zervanos SM. Wild Pig Taxonomy, Morphology, Genetics, and Physiology. In: VerCauteren KC, Beasley JC, Ditchkoff SS, Mayer JJ, Roloff GJ, Strickland BK, editors. Invasive Wild Pigs in North America: Ecology, Impacts, and Management. Boca Raton, FL, USA: CRC Press; 2020. p. [7-32].

32. Pohle J, Langrock R, van Beest FM, Schmidt NM. Selecting the Number of States in Hidden Markov Models: Pragmatic Solutions Illustrated Using Animal Movement. JABES. 2017 Sep 1;22(3):270-93.

33. Kay SL, Fischer JW, Monaghan AJ, Beasley JC, Boughton R, Campbell TA, et al. Quantifying drivers of wild pig movement across multiple spatial and temporal scales. Movement Ecology [Internet]. 2017;5(14). Available from: http://proxy- remote.galib.uga.edu/login?

url=http://search.ebscohost.com/login.aspx?direct=true\&db= edswsc\&AN=000403549100001\&site=eds-live

34. Keuling O, Stier N, Roth M. Annual and seasonal space use of different age classes of female wild boar Sus scrofa L. Eur J Wildl Res. 2009;54(3):403-12.

35. Burnham KP, Anderson DR. Model selection and multimodel inference: a practical informationtheoretic approach. Second. Heidelberg and New York: Springer; 2002.p. 488

36. R Core Team. R: A language and environment for statistical computing. [Internet]. Vienna, Austria: R Foundation for Statistical Computing; 2019. Available from: https://www.R- project.org/

37. Jin S, Homer C, Yang L, Danielson P, Dewitz J, Li C, et al. Overall Methodology Design for the United States National Land Cover Database 2016 Products. Remote Sensing. 2019;11(24):2-32.

38. Calenge $\mathrm{C}$. The package adehabitat for the $\mathrm{R}$ software: a tool for the analysis of space and habitat use by animals. Ecological Modelling. 2006;197(3-4):516-9.

39. Conner LM, Smith MD, Burger LW. A Comparison of Distance-Based and Classification- Base Analyses of Habitat Use. Ecology. 2003;84(2):526-31.

40. Kohl MT, Krausman PR, Kunkel K, Williams DM. Bison Versus Cattle: Are They Ecologically Synonymous? Rangeland Ecology \& Management. 2013;66(6):721-31.

41. Bates D, Mächler M, Bolker B, Walker S. Fitting linear mixed-effects models using Ime4. arXiv:14065823 [stat] [Internet]. 2014 Jun 23 [cited 2020 Jan 6]; Available from: http://arxiv.org/abs/1406.5823 
42. Fielding $\mathrm{AH}$, Bell JF. A review of methods for the assessment of prediction errors in conservation presence/absence models. Environmental Conservation. 1997;24(1):38-49.

43. Zipkin EF, Grant EHC, Fagan WF. Evaluating the predictive abilities of community occupancy models using AUC while accounting for imperfect detection. Ecological Applications. 2012;22(7):1962-72.

44. Latif QS, Saab VA, Dudley JG, Markus A, Mellen-McLean K. Development and evaluation of habitat suitability models for nesting white-headed woodpecker (Dryobates albolarvatus) in burned forest. PLoS One; San Francisco. 2020;15(5):e0233043.

45. Robin X, Turck N, Hainard A, Tiberti N, Lisacek F, Sanchez J-C, et al. pROC: an open- source package for $\mathrm{R}$ and $\mathrm{S}+$ to analyze and compare ROC curves. BMC Bioinformatics. 2011 Mar 17;12(1):77.

46. Manly BFJ, McDonald LL, Thomas DL, McDonald TL, Erickson WP. Resource selection by animals: statistical analysis and design for field studies. Nordrecht, The Netherlands: Kluwer Academic Publishers; 2002.

47. Gillies CS, Hebblewhite M, Nielsen SE, Krawchuk MA, Aldridge CL, Frair JL, et al. Application of Random Effects to the Study of Resource Selection by Animals. Journal of Animal Ecology. 2006;75(4):887-98.

48. Karelus DL, McCown JW, Scheick BK, Kerk M van de, Bolker BM, Oli MK. Incorporating movement patterns to discern habitat selection: black bears as a case study. Wildlife Res. 2019;46(1):76-88.

49. Comer CE, Mayer JJ. Wild pig reproductive biology. In: Mayer JJ, Brisbin IL, editors. Wild pigs: biology, damage, control techniques and management. Savannah River Site Aiken, SC, USA: Savannah River Nuclear Solutions LLC; 2009. p. [51-75].

50. Snow NP, Miller RS, Beasley JC, Pepin KM. Wild pig population dynamics. In: VerCauteren KC, Beasley JC, Ditchkoff SS, Mayer JJ, Roloff GJ, Strickland BK, editors. Invasive wild pigs in North America: ecology, impacts, and management. Boca Raton, FL, USA: CRC Press; 2020. p. [57-82].

51. Matiuti M, Bogdan AT, Crainiceanu E, Matiuti C. Research regarding the hybrids resulted from the domestic pig and the wild boar. Scientific Papers. 2010;43(1):188-191.

52. Abrahms B, Jordan NR, Golabek KA, McNutt JW, Wilson AM, Brashares JS. Lessons from integrating behaviour and resource selection: activity-specific responses of African wild dogs to roads. Animal Conservation. 2016;19(3):247-55.

53. Ditchkoff SS, Mayer JJ. Wild pig food habits. In: Mayer JJ. Brisbin IL, editors. Wild pigs: biology, damage, control techniques and management. Savannah River Site Aiken, SC, USA: Savannah River Nuclear Solutions LLC; 2009. p. [105-143].

54. Ballari SA, Barrios-García MN. A review of wild boar Sus scrofa diet and factors affecting food selection in native and introduced ranges. Mammal Review. 2014;44(2):124-34.

55. Lewis JS, VerCauteren KC, Denkhaus RM, Mayer JJ. Wild pig populations along the urban gradient. In: Invasive wild pigs in North America: ecology, impacts, and management. Boca Raton, FL, USA: CRC Press; 2020. p. 439-64.

56. Podgórski T, Baś G, Jędrzejewska B, Sönnichsen L, Śnieżko S, Jędrzejewski W, et al. Spatiotemporal Loading [MathJax]/jax/output/CommonHTML/fonts/TeX/fontdata.js contrasting conditions of human pressure: 
primeval forest and metropolitan area. J Mammal. 2013 Feb 15;94(1):109-19.

57. Castillo-Contreras R, Carvalho J, Serrano E, Mentaberre G, Fernández-Aguilar X, Colom A, et al. Urban wild boars prefer fragmented areas with food resources near natural corridors. Science of The Total Environment. 2018 Feb 15;615:282-8.

58. Brown GP, Phillips BL, Webb JK, Shine R. Toad on the road: Use of roads as dispersal corridors by cane toads (Bufo marinus) at an invasion front in tropical Australia. Biological Conservation. 2006 Nov 1;133(1):88-94.

59. Thurfjell H, Ball JP, Åhlén P-A, Kornacher P, Dettki H, Sjöberg K. Habitat use and spatial patterns of wild boar Sus scrofa (L.): agricultural fields and edges. Eur J Wildl Res. 2009 Oct 1;55(5):517-23.

60. Senior AM, Grueber CE, Machovsky-Capuska G, Simpson SJ, Raubenheimer D. Macronutritional consequences of food generalism in an invasive mammal, the wild boar. Mammalian Biology. 2016 Sep 1;81(5):523-6.

61. Lyons PC, Okuda K, Hamilton MT, Hinton TG, Beasley JC. Rewilding of Fukushima's human evacuation zone. Frontiers in Ecology and the Environment. 2020;18(3):127-34.

62. Graves HB. Behavior and ecology of wild and feral Swine (Sus Scrofa). J Anim Sci. 1984 Feb 1;58(2):482-92.

63. Dardaillon M. Seasonal variations in habitat selection and spatial distribution of wild boar (Sus Scrofa) in the Camargue, Southern France. Behavioural Processes. 1986 Sep;13(3):251-68.

64. Meriggi A, Sacchi O. Habitat requirements of wild boars in the northern Apennines ( $\mathrm{N}$ Italy): A multilevel approach. Italian Journal of Zoology. 2001 Jan 1;68(1):47-55.

\section{Figures}
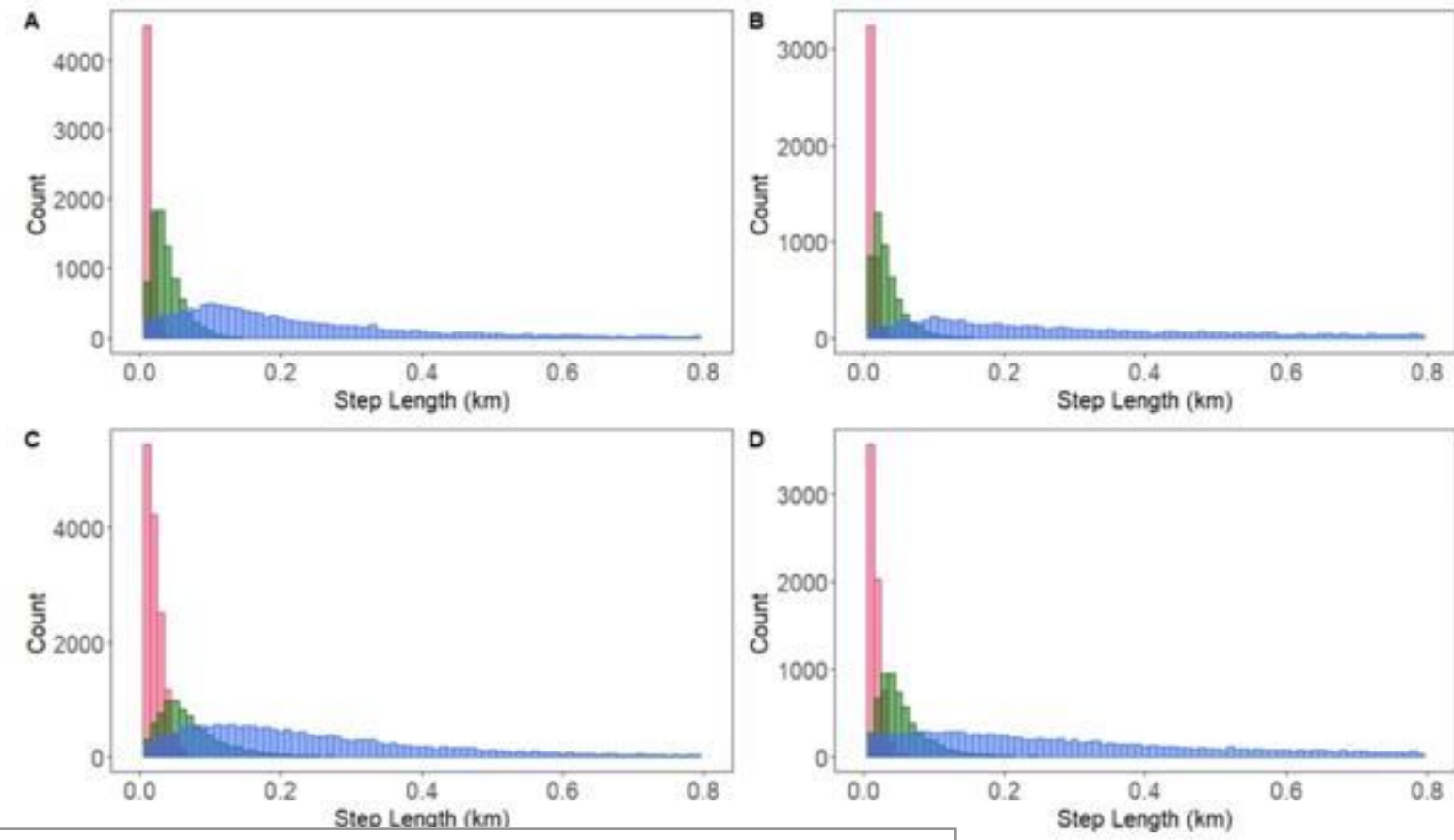
Figure 1

Step-length parameter distributions from three-state hidden Markov models (HMMs) for wild pigs (Sus scrofa)in the Southeast USA by sex and season: (A) females in low-forage months (January - April); (B) males in low-forage months; (C) females in high-forage months (May - December); (D) males in highforage months.
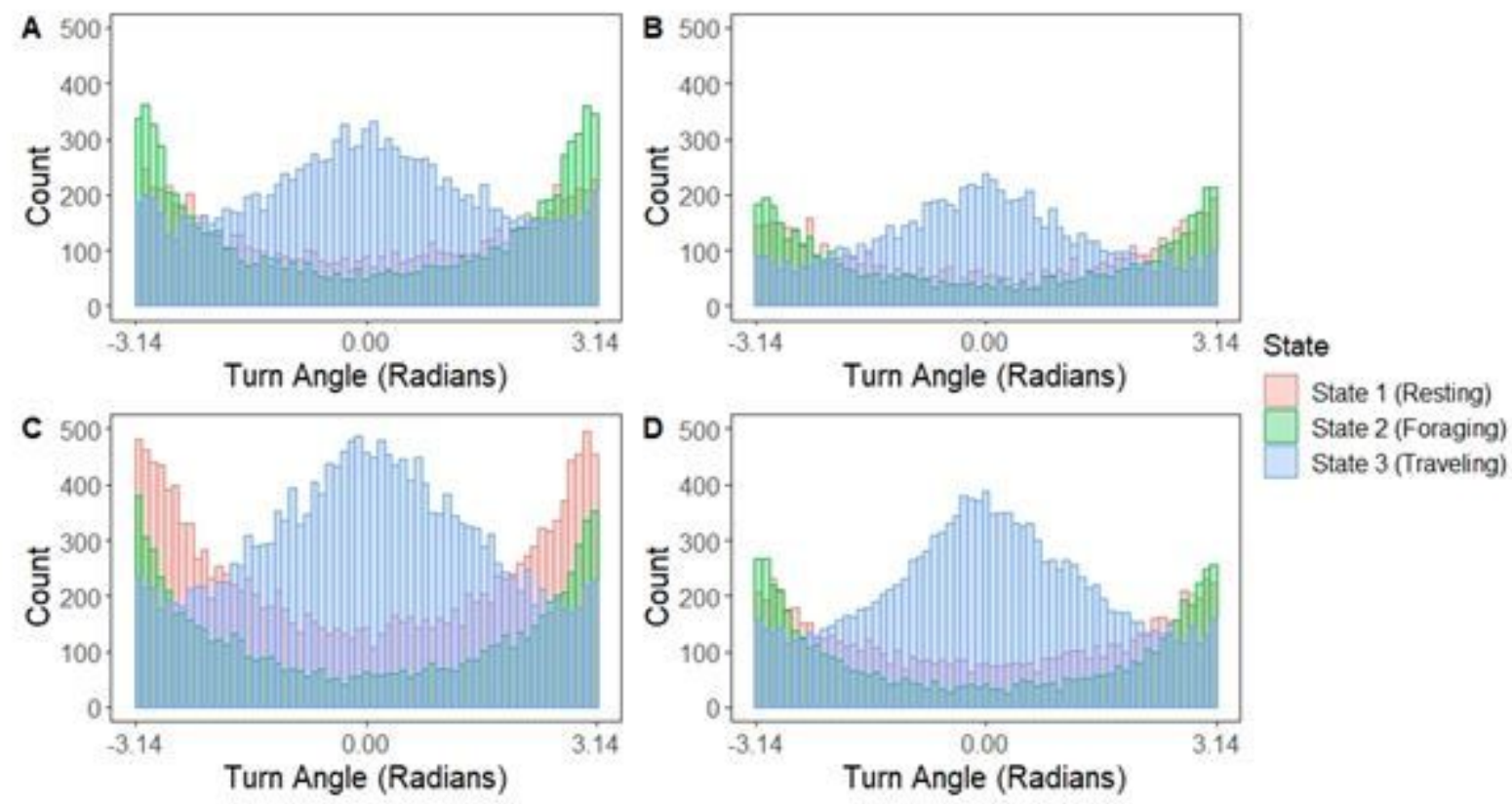

\section{Figure 2}

Turn angle parameter distributions from three-state hidden Markov models (HMMs) for wild pigs (Sus scrofa)in the Southeast USA by sex and season: (A) females in low-forage months (January - April); (B) males in low-forage months; (C) females in high-forage months (May - December); (D) males in highforage months. 

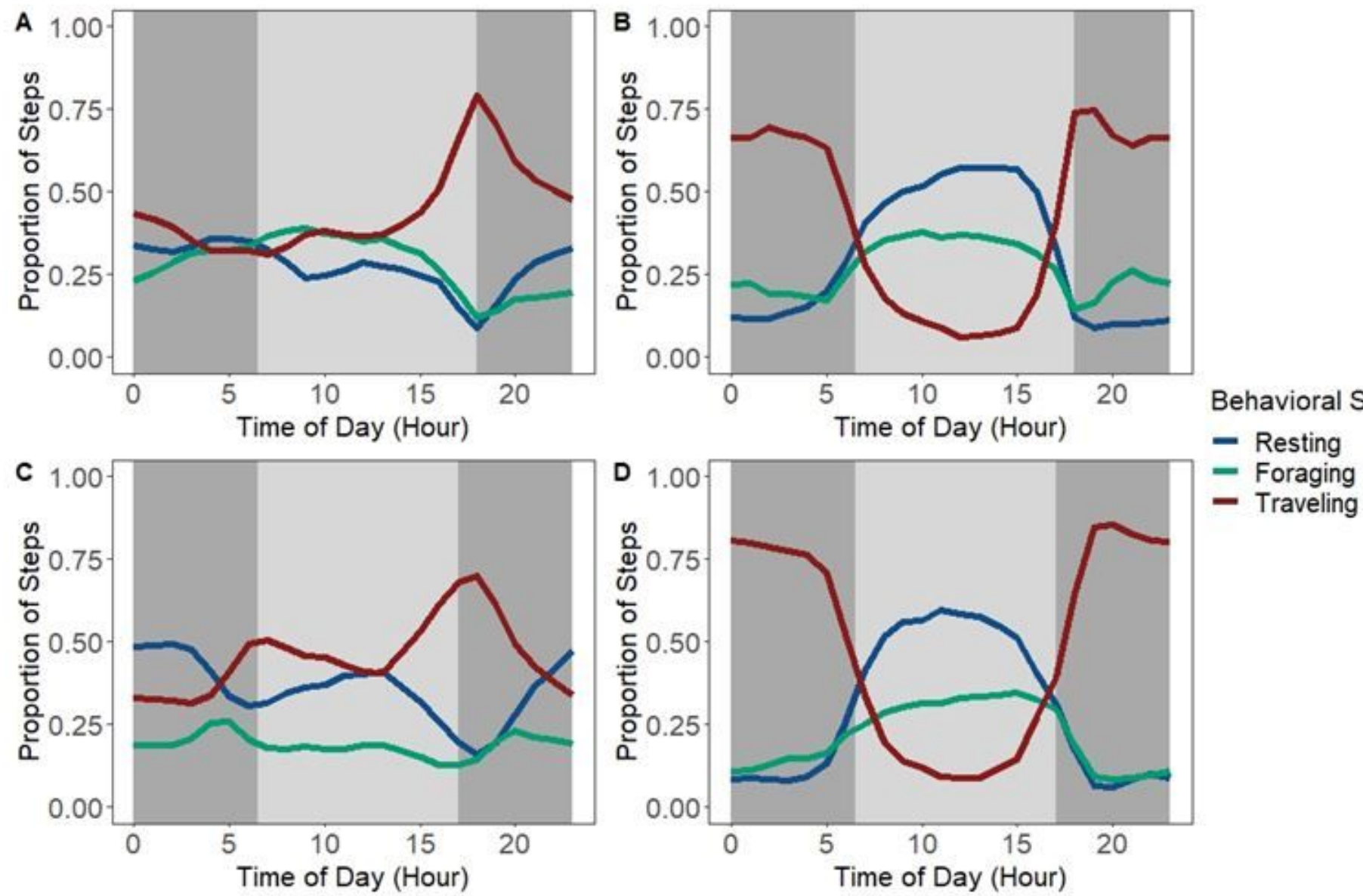

\section{Figure 3}

Proportion of steps per hour for each behavioral state of wild pigs (Sus scrofa)on the Savannah River Site in South Carolina and Georgia by sex and season: (A) females in low-forage months (January April); (B) males in low-forage months; (C) females in high-forage months (May - December); (D) males in high-forage months. The dark gray bars represent average nighttime hours while the light gray bar represents the average daytime hours. 


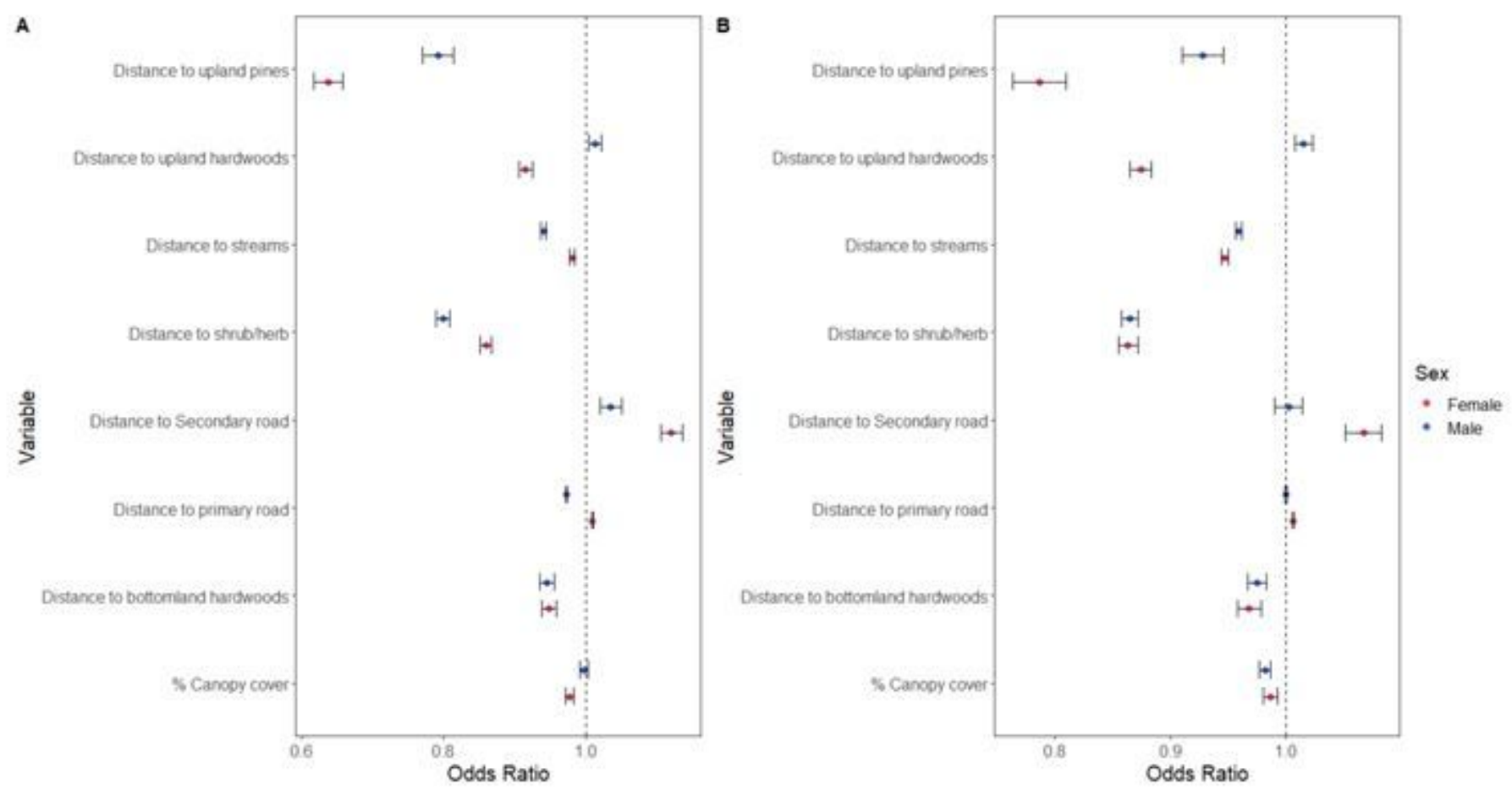

\section{Figure 4}

Predictive odds with 95\% confidence intervals for second order selection (Johnson 1980) of female and male wild pigs (Sus scrofa)on the Savannah River Site in South Carolina and Georgia during two distinct seasons based on forage availability, (A) low-forage availability (January - April) and (B) high-forage availability (May - December) for every $100 \mathrm{~m}$ for distance variables and every 10\% for canopy cover. For distance variables, values less than 1 along with confidence intervals that do not overlap 1 indicate that wild pigs avoided areas farther away from these covariates (i.e., selected areas near or in these variable types), and values greater than 1 with confidence intervals that do not overlap 1 indicate wild pigs selected areas farther away from these covariates (i.e., avoided areas near or in these variable types). For non-distance variables (e.g., \% canopy cover), values greater than 1 along with confidence intervals that do not overlap 1 indicate wild pigs selected for this variable, while values less than 1 along with confidence intervals that do not overlap 1 indicate wild pigs avoided this variable. In cases where the confidence interval crosses 1 , the variable is considered not significant. 


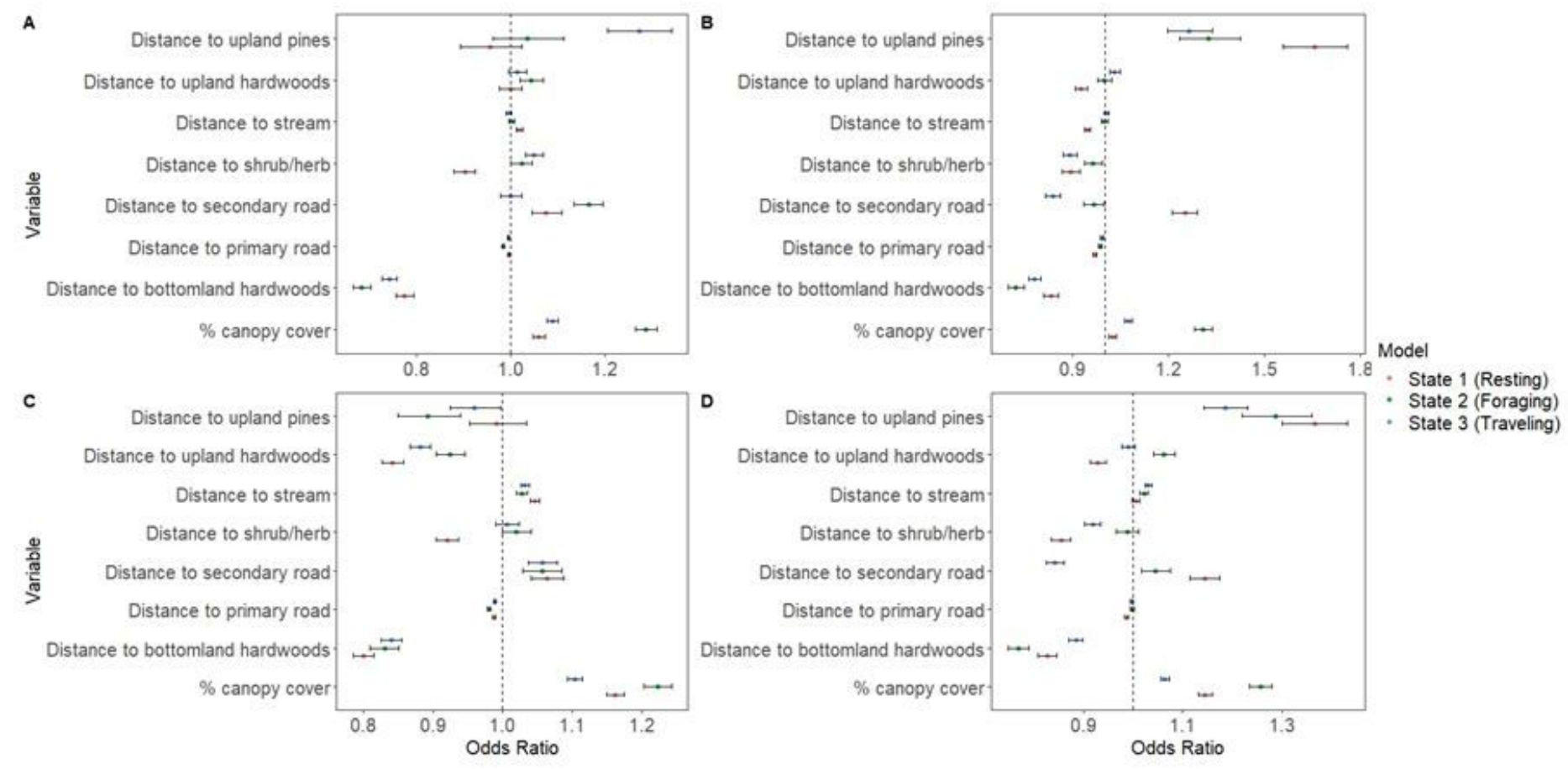

\section{Figure 5}

Predictive odds with 95\% confidence intervals of a wild pig (Sus scrofa)on the Savannah River Site in South Carolina and Georgia during two distinct seasons based on forage availability, low-forage availability (January - April) and high-forage availability (May - December), selecting or avoiding vegetation types, streams, characteristics of development (e.g., roads)for every 100 mand canopy cover for every $10 \%$ by state where states represent resting, foraging, and traveling behaviors, respectively: (A) Females in low-forage months (January - April); (B) males in low-forage months; (C) females in highforage months (May - December); (D) males in high-forage months.For distance variables, values less than 1 along with confidence intervals that do not overlap 1 indicate that wild pigs avoided areas farther away from these covariates (i.e., selected areas near or in these variable types), and values greater than 1 with confidence intervals that do not overlap 1 indicate wild pigs selected areas farther away from these covariates (i.e., avoided areas near or in these variable types). For non-distance variables (e.g., \% canopy cover), values greater than 1 along with confidence intervals that do not overlap 1 indicate wild pigs selected for this variable, while values less than 1 along with confidence intervals that do not overlap 1 indicate wild pigs avoided this variable. In cases where the confidence interval crosses 1 , the variable is considered not significant.

\section{Supplementary Files}

This is a list of supplementary files associated with this preprint. Click to download. 